\title{
Arteriovenous malformation in association with moyamoya disease
}

\section{Report of two cases}

Toshihiko Nakashima, M.D., Noriyuki Nakayama, M.D., Masahiro Furuichi, M.D., Jouji Kokuzawa, M.D., Takatsugu Murakawa M.D., and Noboru Sakai, M.D.

Department of Neurosurgery, Takayama Red Cross Hospital; Department of Neurosurgery, Ehime Rosai Hospital; and Department of Neurosurgery, Gifu University School of Medicine, Gifu, Japan

The authors report two rare cases of arteriovenous malformation (AVM) associated with moyamoya disease. An AVM, supplied by transdural communicating arteries, was located in the right occipital lobe in one patient who presented with ischemia. The second AVM, which was supplied by basal moyamoya vessels, was located in the posterior part of the left frontal lobe in a patient who developed intracerebral hemorrhage that occupied the left basal ganglion.

A review of the literature revealed a total of 12 AVMs in 11 patients with moyamoya disease including our cases. All AVMs were cerebral and two were supplied by normal cerebral arteries, whereas six AVMs were supplied by basal moyamoya vessels at the base of the brain and four AVMs were supplied by external carotid arteries through the transdural communicating arteries. Every AVM drained into deep or cortical cerebral veins. These findings suggest that the hyperangiogenic character of moyamoya disease occasionally induces the development of acquired arteriovenous shunts that mimic AVM.

Key Words * moyamoya disease * arteriovenous malformation * collateral circulation

The incidence of arteriovenous malformation (AVM) in association with moyamoya disease and occlusive vascular disease in bilateral internal carotid artery (ICA) systems is extremely rare in contrast to the incidence of saccular aneurysms in patients with this disease.[1,3-8] The pathogenesis and prognosis in patients with AVMs remain unclear, although the possible role of hemodynamic stress has been suggested to account for the pathogenesis of saccular aneurysms in these patients. In this paper, we describe two patients with moyamoya disease in whom an AVM was found, and we discuss the pathogenesis of the combination of two different vascular diseases.

\section{CASE REPORTS}

\section{Case 1}

This 37-year-old man presented with right-sided hemiparesis that had begun 3 months earlier. His right 
arm weakness had improved within 1 month; however, his leg weakness persisted. At the age of 8 years, he had experienced a transient episode of gait disturbance, although he did not remember noticing hemiparesis at that age. Thereafter his mental development has been delayed. Neurological examination on admission revealed left leg weakness; neuropsychological test estimated his intelligence quotient score to be 60. Magnetic resonance imaging showed bilateral frontal and temporooccipital watershed infarction and vascular channels that were suggestive of AVM in the right occipital lobe (Fig. 1).

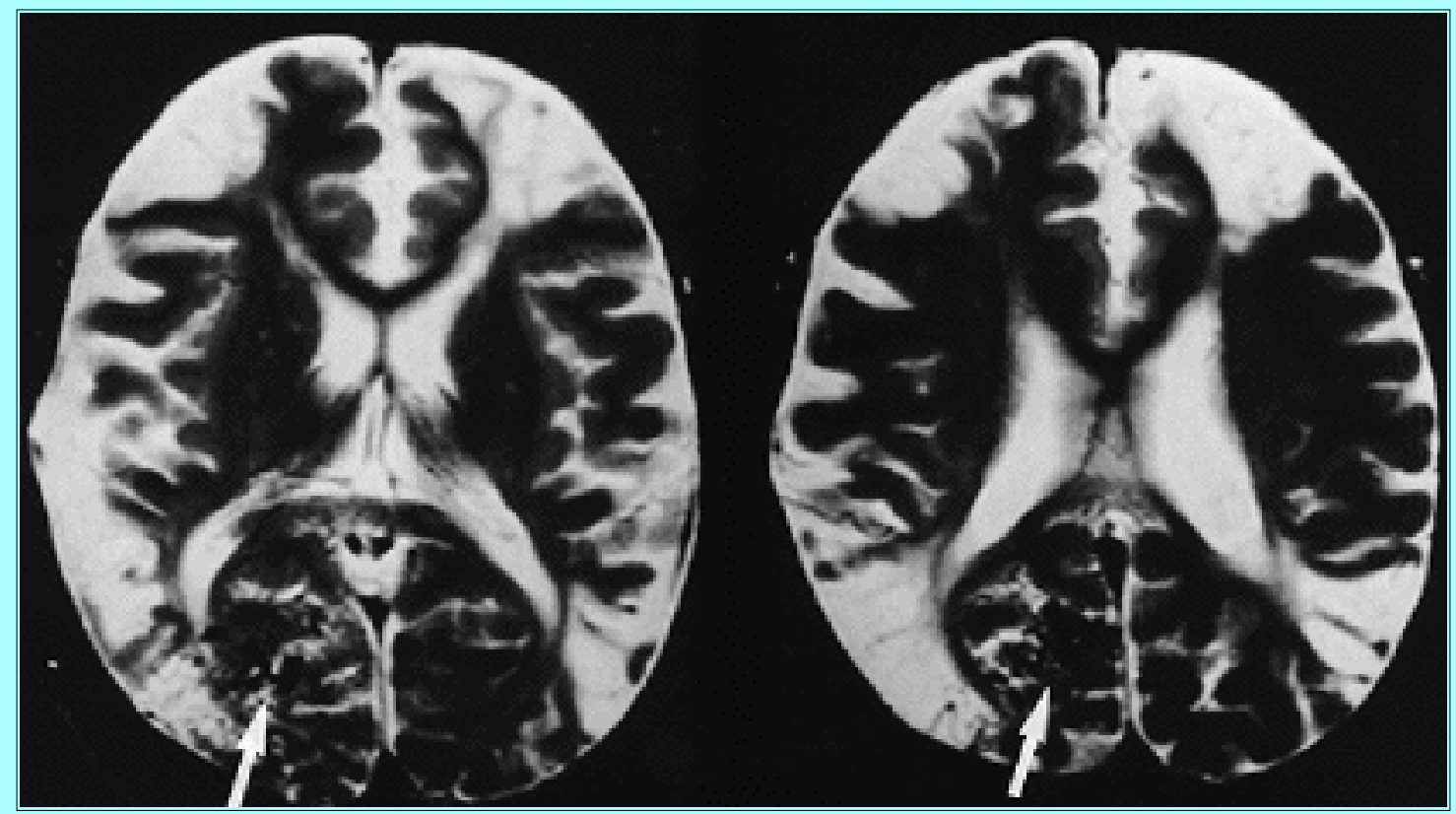

Fig. 1. Case 1. Axial $\mathrm{T}_{2}$-weighted magnetic resonance images showing bilateral frontal and temporooccipital watershed infarction and flow void of AVM in the right occipital lobe (arrow).

Common carotid artery angiography revealed ICA occlusion above the ophthalmic arteries with bilateral moyamoya vessels at the base of the brain. An AVM supplied by transdural communicating arteries was revealed in the right occipital lobe (Fig. 2). The patient underwent bilateral encephaloduroarteriosynangiosis; however, his neurological status remained unchanged. Follow-up angiography performed 1 year after initial angiography revealed no significant vascular change. 


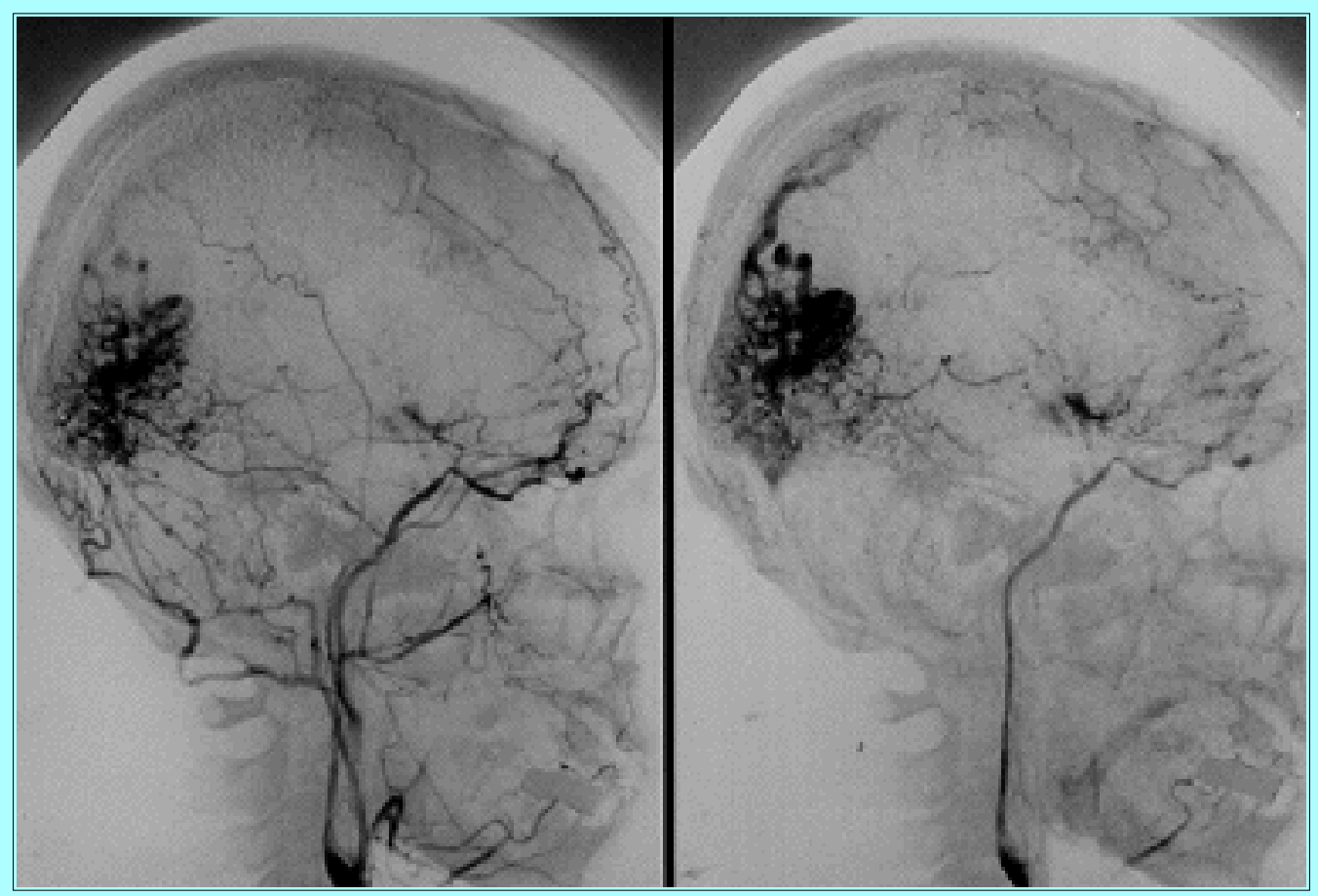

Fig. 2. Case 1. Right common carotid artery angiograms showing a right occipital lobe AVM that is supplied by transdural collateral vessels and drained into the ascending veins.

\section{Case 2}

This 44-year-old previously healthy woman developed a headache, subsequent emesis, and loss of consciousness. On admission, she was stuporous and showed decerebrated posture movements on the right side. Computerized tomography scanning revealed an intracerebral hematoma that occupied the left basal ganglion and extended to the temporal lobe (Fig. 3).

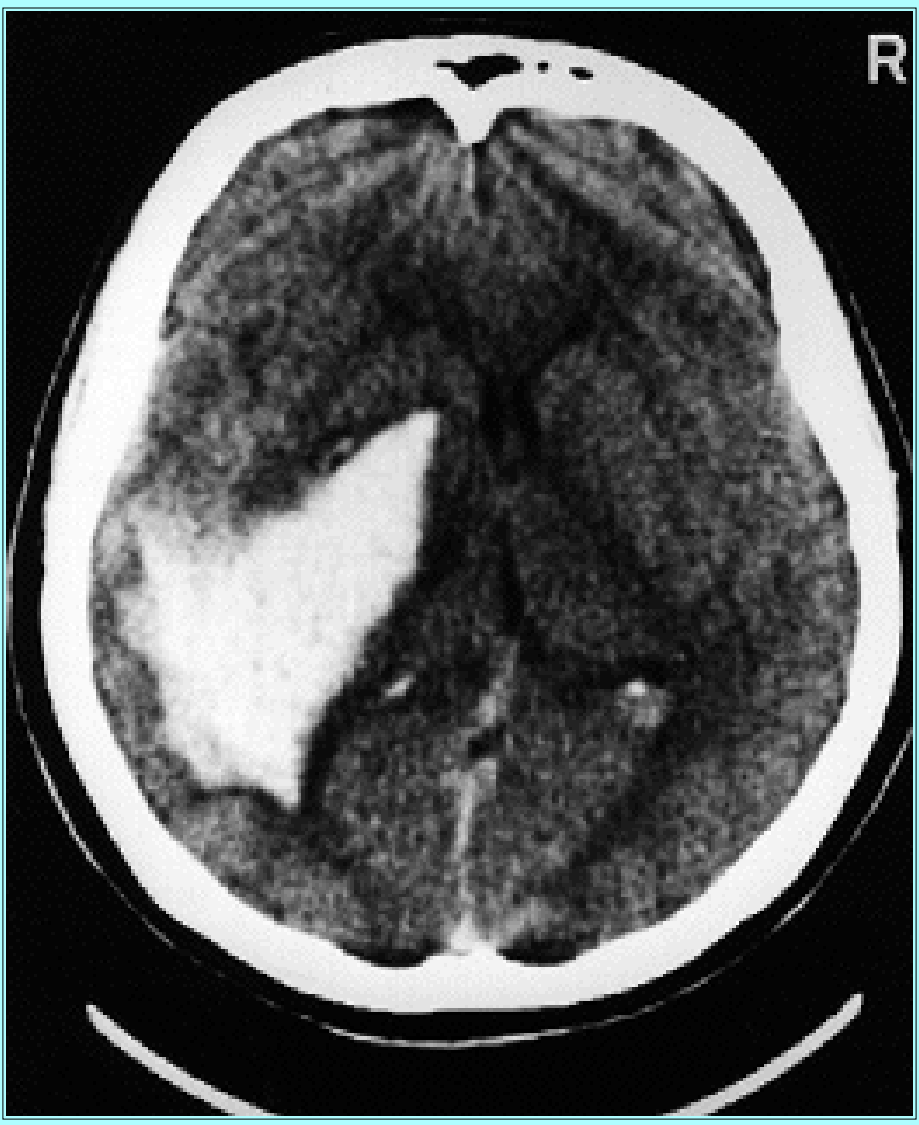


Fig. 3. Case 2. Computerized tomography scans obtained at admission revealing an intracerebral hemorrhage that occupies the left basal ganglion and extends to the temporal lobe.

Common carotid artery angiography demonstrated occlusion of the bilateral ICA at the supraclinoid portion with moyamoya vessels. Angiography unexpectedly revealed an AVM, which was supplied by basal moyamoya vessels and drained into the internal cerebral vein and tortuous sylvian vein, at the base of the left frontal lobe (Fig. 4).

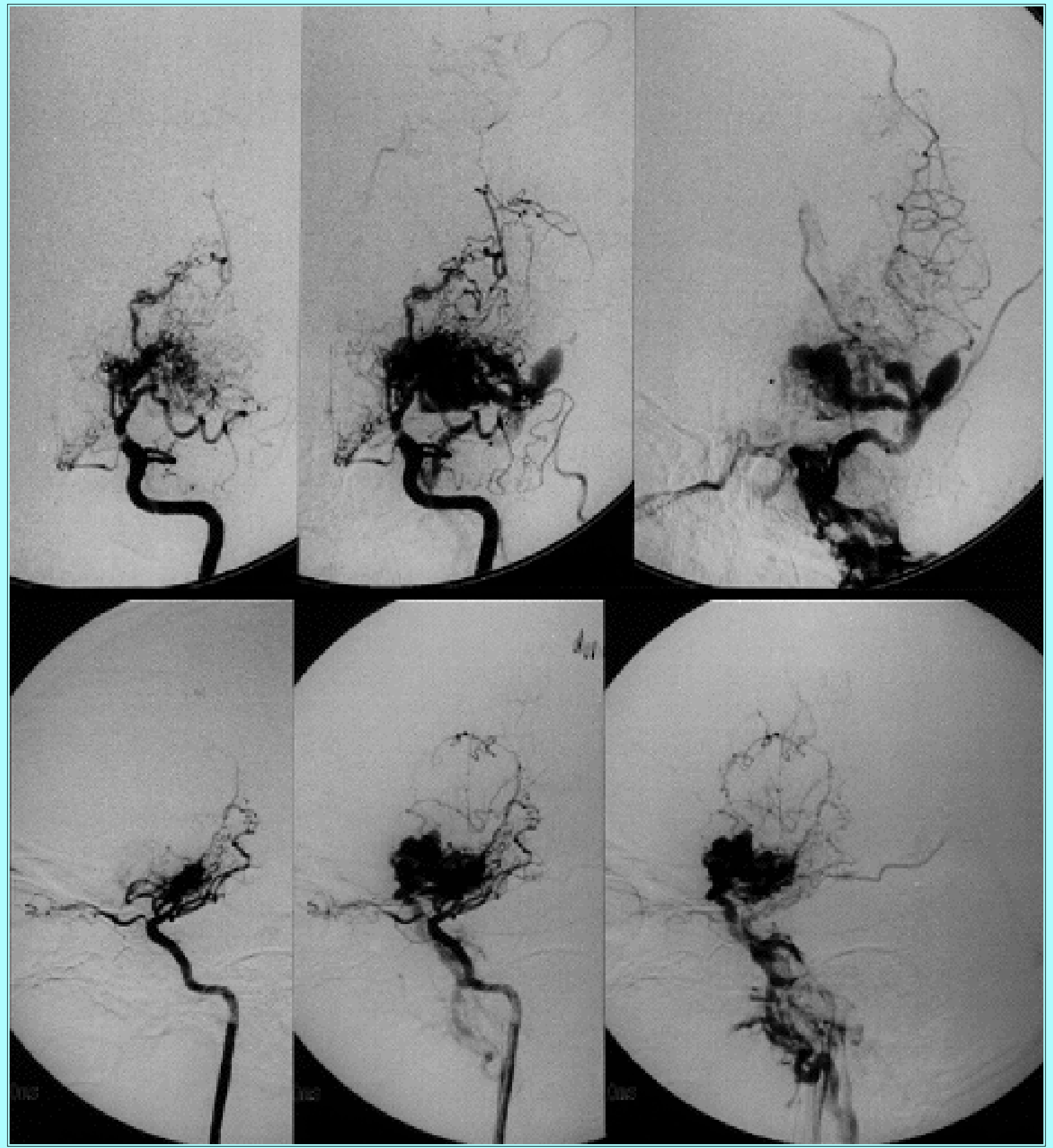

Fig. 4. Case 2. Left common carotid artery angiograms, Town's projection (upper) and lateral projection (lower), showing AVM supplied by basal moyamoya vessels and drained to sylvian vein and internal cerebral vein.

However, we could not discern from the angiogram whether the intracerebral hematoma was induced by 
rupture of the AVM or by the fragile moyamoya vessels. Because the dissection of the vascular malformation from the adjacent moyamoya vessels was considered to be too difficult, the patient was managed conservatively. She regained consciousness over the following 3 weeks; however, her right-sided hemiparesis and aphasia persisted. Repeat angiography 1 year postictus demonstrated no significant vascular change and magnetic resonance imaging demonstrated flow void of basal moyamoya vessels and an AVM at the base of the left frontal lobe adjacent to porencephaly after the intracerebral hemorrhage; however, it was impossible to discriminate between moyamoya vessels and the AVM (Fig. 5). The patient experienced no more hemorrhagic episodes during the subsequent 4 years.

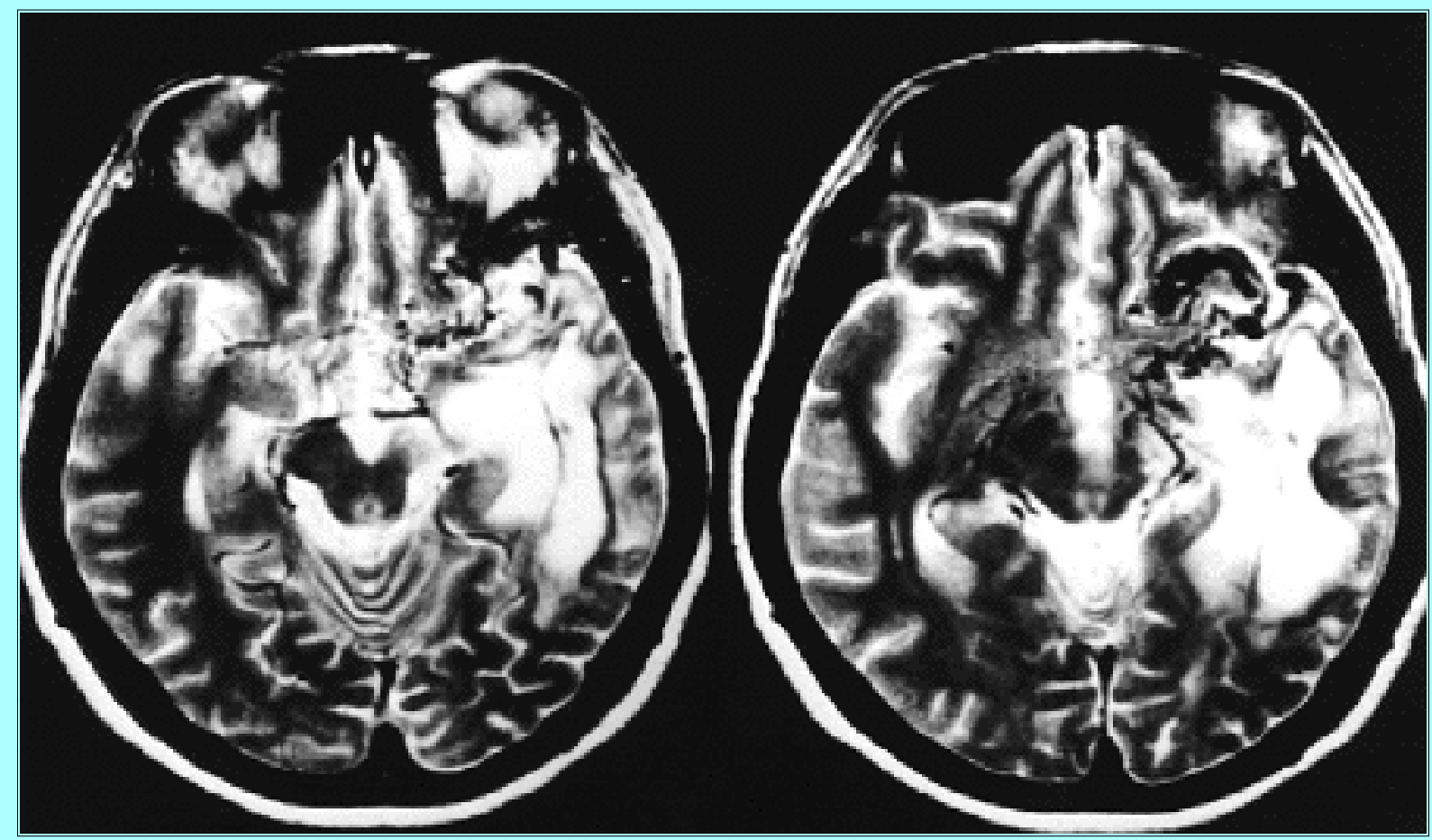

Fig. 5. Axial $\mathrm{T}_{2}$-weighted magnetic resonance images obtained 1 year after ictus showing flow void of basal moyamoya vessels and AVM adjacent to the porencephaly after intracerebral hemorrhage.

\section{DISCUSSION}

In contrast to cerebral aneurysms, AVMs associated with moyamoya disease are extremely rare. A total of twelve AVMs in association with eleven cases of moyamoya disease have been reported (Table 1). $[1,3-8]$ 


\begin{tabular}{|c|c|c|c|c|}
\hline Authors \& Year & $\begin{array}{c}\text { Age }(y>3) \\
\text { Sex }\end{array}$ & Signs \& Symptoms & Locali on of A'vly & Feeding Arteri es \\
\hline $\begin{array}{l}\text { Mamad, et al., } \\
1984\end{array}$ & $27, \mathrm{~F}$ & not specified & basal ganglia & striate tranch of MCA, \\
\hline $\begin{array}{l}\text { Kayama, et al., } \\
1986\end{array}$ & $33, M$ & $\begin{array}{l}\text { It hemi paresis, im paired visual } \\
\text { acuity, cerebral infarction (rt } \\
\text { tem poral, ocdital) }\end{array}$ & rt frontal & basal mul vessels \\
\hline \multirow{4}{*}{$\begin{array}{l}\text { Lichtor \& } \\
\text { Mullan, } 1987\end{array}$} & $34, M$ & $\begin{array}{l}\text { It hemi plegia, } \\
\text { in traceretral hemormage? }\end{array}$ & corruscallosum & tasal MM wessels TP \\
\hline & & & & $\begin{array}{l}\text { artery post choroidal } \\
\text { artery }\end{array}$ \\
\hline & & $\begin{array}{l}\text { It num tness \& hemi paresis, } \\
\text { cerebral infarction (rt parietal) }\end{array}$ & rt parie totem poral & basal MM wessels \\
\hline & $43, M$ & $\begin{array}{l}\text { It hemi plegia, seizure; } \\
\text { rt thalamic hemormage }\end{array}$ & rt frontocentral & basal MM wessels \\
\hline $\begin{array}{l}\text { Montanera, et } \\
\text { al., } 1990\end{array}$ & $54, F$ & $\begin{array}{l}\text { transient it hand num bness, } \\
\text { word-finding diffoulty }\end{array}$ & $\begin{array}{l}\text { rt frontal \& It } \\
\text { frontal }\end{array}$ & both in TDC ve ssels \\
\hline $\begin{array}{l}\text { Okada, et al., } \\
1990\end{array}$ & $38, F$ & $\begin{array}{l}\text { It numbness \& hemi pare sis } \\
\text { cerebral infarction (lt fron tal) }\end{array}$ & It frontal & It premolandic artery \\
\hline $\begin{array}{l}\text { Akiyama, et } \\
\text { al., } 1994\end{array}$ & $42, F$ & $\begin{array}{l}\text { loss of consciousness, } \\
\text { rt caudate hemorhage }\end{array}$ & It frontal & $\begin{array}{l}\text { medial striate artery } \\
\text { TDC uessels }\end{array}$ \\
\hline $\begin{array}{l}\text { Schmit, et al., } \\
1996\end{array}$ & $11, M$ & $\begin{array}{l}\text { rt hemi paresis, seizure, } \\
\text { cerebral infarction (lt frontal, } \\
\text { parietal) }\end{array}$ & It post perietal & TT collat wessels \\
\hline \multirow[t]{2}{*}{ current report } & $37, M$ & $\begin{array}{l}\text { rt hemi paresis, ceretral } \\
\text { in farction (tilat frontal } \& \\
\text { tem poroocd pital) }\end{array}$ & rt occipital & TDC we ssels \\
\hline & $44, F$ & $\begin{array}{l}\text { rt hemi plegia, It putaminal } \\
\text { hemorrhage }\end{array}$ & It frontal & basal MM wessels \\
\hline
\end{tabular}

* ant $=$ anterior; $M C A=$ middle ceretral artery, MM = mo yamoya; post = posterior; TDC = transdural communicating; $T=$ transthalamic; TP $=$ thal amoperforating.

In all cases, occlusive vascular disease with moyamoya vessels was demonstrated on cerebral angiography in the bilateral terminal portion of the ICA or the origin of the anterior cerebral and middle cerebral arteries. Two independent AVMs were present in the bilateral frontal lobe in one patient.[6] Six of the patients presented after ischemic attacks, and four patients developed intracerebral hemorrhages. One patient suffered from a caudate hemorrhage in the contralateral side of the AVM.[1] Two patients sustained intracerebral hemorrhages in the thalamus[4] and basal ganglion, respectively, near the nidus of AVM; however, it was unclear whether the hemorrhage was due to rupture of the AVM or the fragile moyamoya collateral vessels. Based on neurological signs one patient was presumed to be developing an intracerebral hemorrhage, which was not documented.[4] The patient who experienced hemorrhage in the thalamus had a 28-year history of seizures;[4] there have been no other descriptions of patients who presented with seizures. Eleven AVMs were located in the cerebral hemisphere and one in the corpus callosum. Two AVMs were supplied by normal cerebral arteries, whereas 10 AVMs in nine cases were supplied by moyamoya collateral vessels. Six of the AVMs were supplied by moyamoya vessels at the base of the brain, and four were supplied by external carotid arteries through transdural communicating arteries. In all cases except one, in which venous drainage was not reported, the AVMs drained into cerebral veins that were sometimes tortuous or abnormally dilated.

The pathogenesis of AVMs associated with moyamoya disease remains unclear. It is possible that these two independent vascular diseases may occur in one patient. Two AVMs have been described that were 
supplied, not by the moyamoya collateral vessels, but by normal cerebral arteries. These cases might be the coincidence of moyamoya disease and AVM. However, on reviewing the literature, it is noticeable that 10 out of 12 AVMs in patients with moyamoya disease were supplied by moyamoya collateral vessels at the base of the brain or by transdural communicating arteries. Furthermore, Schmit, et al.,[8] have reported a patient with moyamoya disease in whom the development of an AVM was demonstrated by repeated angiography over a 9-year period.[8] Examination of these facts suggests that such AVMs were not congenital lesions but acquired arteriovenous shunts that developed as a consequence of angiogenic failure. In patients with moyamoya disease, hyperangiogenic character was suggested by significantly elevated levels of basic fibroblast growth factor in the cerebrospinal fluid compared to the patients with atherosclerotic occlusive disease.[9] Furthermore, accumulation of basic fibroblast growth factor in the intima and media of the superficial temporal artery in patients with moyamoya disease has also been demonstrated.[2] The hyperangiogenic character plays an important role in the development of the collateral vessels following the progressive stenosis of the cerebral arteries; however, this in turn possibly leads to development of the arteriovenous shunt that mimics an AVM.

The histological differences between the congenital AVM and the AVM associated with moyamoya disease have not been elucidated. One AVM located in the parietal lobe in a patient with moyamoya disease was resected and verified to have the same histological features as congenital AVM.[7] However, the AVM was not supplied by moyamoya collateral vessels but by the prerolandic artery. The case was described as a coincidence of AVM and moyamoya disease. Hence, it does not always imply the general histological appearance of the AVM in association with moyamoya disease. No other AVMs have been examined histologically; therefore, it remains unclear whether or not the AVM associated with moyamoya disease is histologically different from congenital AVM.

In conclusion, we present two patients in whom moyamoya disease was accompanied by an AVM. Although the coexistence of moyamoya disease and AVMs may be a rare coincidence in some cases, it is more likely that the hyperactive angiogenesis led to the formation of acquired arteriovenous shunts in these patients.

\section{References}

1. Akiyama K, Minakawa T, Tsuji Y, et al: Arteriovenous malformation associated with moyamoya disease: case report. Surg Neurol 41:468-471, 1994

2. Hoshimaru M, Takahashi JA, Kikuchi H, et al: Possible roles of basic fibroblast growth factor in the pathogenesis of moyamoya disease: an immunohistochemical study. J Neurosurg 75:267-270, 1991

3. Kayama T, Suzuki S, Sakurai Y, et al: A case of moyamoya disease accompanied by an arteriovenous malformation. Neurosurgery 18:465-468, 1986

4. Lichtor T, Mullan S: Arteriovenous malformation in moyamoya syndrome. Report of three cases. J Neurosurg 67:603-608, 1987

5. Mawad ME, Hilal SK, Michelsen WJ, et al: Occlusive vascular disease associated with cerebral arteriovenous malformations. Radiology 153:401-408, 1984

6. Montanera W, Marotta TR, terBrugge KG, et al: Cerebral arteriovenous malformations associated with moyamoya phenomenon. AJNR 11:1153-1156, 1990 
7. Okada T, Kida Y, Kinomoto T, et al: Arteriovenous malformation associated with moyamoya disease--case report. Neurol Med Chir 30:945-948, 1990

8. Schmit BP, Burrows PE, Kuban K, et al: Acquired cerebral arteriovenous malformation in a child with moyamoya disease. Case report. J Neurosurg 84:677-680, 1996

9. Takahashi A, Sawamura Y, Houkin K, et al: The cerebrospinal fluid in patients with moyamoya disease (spontaneous occlusion of the circle of Willis) contains high level of basic fibroblast growth factor. Neurosci Lett 160:214-216, 1993

Manuscript received May 27, 1998.

Accepted in final form October 19, 1998.

Address reprint requests to: Toshihiko Nakashima, M.D., Department of Neurosurgery, Takayama Red Cross Hospital, 3-11 Tenmancho Takayama, Gifu 506-8550, Japan. 